\title{
The way out
}

Citation for published version (APA):

Baeten, C. G. M. I. (2014). The way out: Afscheidsrede van Cor G.M.I. Baeten. Maastricht University. https://doi.org/10.26481/spe.20140404cb

Document status and date:

Published: 01/01/2014

DOI:

$10.26481 / \mathrm{spe} .20140404 \mathrm{cb}$

Document Version:

Accepted author manuscript (Peer reviewed / editorial board version)

\section{Please check the document version of this publication:}

- A submitted manuscript is the version of the article upon submission and before peer-review. There can be important differences between the submitted version and the official published version of record.

People interested in the research are advised to contact the author for the final version of the publication, or visit the DOI to the publisher's website.

- The final author version and the galley proof are versions of the publication after peer review.

- The final published version features the final layout of the paper including the volume, issue and page numbers.

Link to publication

\footnotetext{
General rights Owners
rights.

- You may freely distribute the URL identifying the publication in the public portal. please follow below link for the End User Agreement:

www.umlib.nl/taverne-license

Take down policy

If you believe that this document breaches copyright please contact us at:

repository@maastrichtuniversity.nl

providing details and we will investigate your claim.
}

Copyright and moral rights for the publications made accessible in the public portal are retained by the authors and/or other copyright owners and it is a condition of accessing publications that users recognise and abide by the legal requirements associated with these

- Users may download and print one copy of any publication from the public portal for the purpose of private study or research.

- You may not further distribute the material or use it for any profit-making activity or commercial gain

If the publication is distributed under the terms of Article $25 \mathrm{fa}$ of the Dutch Copyright Act, indicated by the "Taverne" license above, 
Cor G.M.I. Baeten

Faculty of Health, Medicine and Life Sciences

The way out 
The way out

Mijnheer de rector, confratres,

consorores uit de AZM familie, eigen familie, vrienden en belangstellenden. 38 jaar geleden kwam ik als kersvers doktertje uit de collegebanken in Nijmegen om me te specialiseren in de chirurgie in het St. Annadal ziekenhuis in Maastricht. De dag na mijn artsenbuluitreiking begon ik op de EHBO. en werd door mijn ouderejaars collega's wegwijs gemaakt in de behandelingen van chirurgische aandoeningen. Professor Lemmens was destijds opleider en deze werd later opgevolgd door professor Greep. Aan beiden,hoe verschillend ook van karakter en eigenschappen, bewaar ik de beste 
herinneringen. St. Annadal was toen nog een kleinschalig perifeer ziekenhuis waar de net opgerichte medische faculteit zijn intrek nam. De oprichters van de Maastrichtse universiteit hadden grote ambities en deze botsten vaak met de belangen van de nog zittende specialisten, die hun oude koninkrijkjes verdedigden. Overal om ons heen heerste er chaos en ruzie, maar alleen de afdeling chirurgie was een oase van rust. De ambities van de oprichters vond vruchtbare bodem in de chirurgische assistenten groep. Deze groep bestond uit assistenten die deels door Lemmens en deels door Greep waren aangenomen. De assistenten werden tegen elkaar uitgespeeld, maar de animositeit tussen beide generaals had geen invloed op de legers der assistenten. Die konden het uitstekend met elkaar 
vinden en bij gebrek aan strijdlust bleef er voor de generaals niets anders over dan de strijdbijl te begraven. De grote baas toen was de geweldenaar prof. Greep, een van de oprichters van deze universiteit. Hij was het die alle assistenten achter hun broek zat om te promoveren en buitenlandse ervaring op te doen. Hij wilde zijn afdeling opstuwen tot een van de chirurgische topafdelingen in de wereld. Het ambitieniveau van de baas lag zeer hoog, maar het heeft de assistenten behalve stress ook veel goeds gebracht. Ik heb deze inleiding nodig om u een beeld te schetsen van een perifere tent die op het punt staat nieuwe wegen in te slaan. Ik zelf kreeg min of meer de opdracht om eens uit te zoeken of er niet wat andere methodes waren om patiënten met haemorrhoïden te behandelen. We hadden op dat moment 
één boek over colo-rectale chirurgie nog uit de vooroorlogse tijd ,"geëdit “ door een zekere dokter Gabriel. Hierin werd de methode volgens MilliganMorgan beschreven. Zover echter was men nog nooit in het boek gekomen, zodat wij maar één methode kenden om haemorrhoïden te behandelen: en dat was "een Gabriel". Dit was een uiterst pijnlijke behandeling en in de stad was bekend dat dit het meest verschrikkelijke was dat een mens kon overkomen. Vrouwen kregen liever een dozijn kinderen en mannen gaven de voorkeur aan een gruwelijke amputatie van n'importe welk orgaan dan ook. Ik kreeg van toen af alle patiënten die een anaal probleem hadden op mijn spreekuur. Uiteraard was het van belang haemorrhoïden te onderscheiden van andere aandoeningen die bloedverlies per 
anum gaven. Hiertoe gebruikten we tot dan de starre rectoscoop. Deze rectoscoop was een starre buis van 30 $\mathrm{cm}$ die in de anus gebracht werd. De oude polikliniek in Annadal bestond uit een serie piepkleine kamertjes die net groot genoeg waren om een onderzoeksbank te bevatten. De endoscopist nam dan plaats op een kruk die tussen de onderzoeksbank en de deur stond. De patiënt zat geknield op de bank. Zuster Bronckers, hoofd van de poli, had nog al eens de neiging zo het kamertje binnen te vallen om iets te komen bespreken. De kettingreactie die volgde valt te verwachten: een klap van de deur op het achterhoofd van de scopist, een blauw oog van de arts door het oculair en een onverwachte penetratie van de buis door de darm van de patient. Het klinkt dramatischer dan het werkelijk was, maar het schetst 
de primitieve omstandigheden van 35 jaar geleden. Mijn voornemen dus om me te gaan bekwamen in flexibele endoscopieën werd in Nederland bepaald niet met gejuich ontvangen. De internisten zagen een chirurg met dit instrumentarium niet zitten en ik moest uitwijken naar de Verenigde Staten om wat opleiding te krijgen. Een fantastisch jaar in Boston in het Mass. General hospital gaf me alles wat ik maar wensen kon. Ik werd daar aangesteld als opleider van de residents in de chirurgie in het verrichten van endoscopieën en kon gelijk de kunst afkijken bij prof. Steven Hedberg. Ik had bovendien de tijd om aan mijn proefschrift over haemorrhoïden te schrijven. Teruggekomen in Maastricht waren er internisten die mijn activiteiten wel zagen zitten, zoals Pop, Vismans en van Spreeuwel. Vanaf toen 
kreeg mijn leven een wat stabielere basis. Staflid, chirurg en endoscopist, gepromoveerd op haemorrhoïden. De samenwerking met de MDL artsen bleef uitstekend en onder Stockbrüger en Masclé bleef deze vruchtbare samenwerking voortduren.

De studies naar haemorrhoïden leiden tot nieuwe inzichten. Haemorrhoïdaal weefsel is namelijk prachtig weefsel dat ieder mens nodig heeft om continent te kunnen zijn. Binnen de gecontraheerde sfincter zal altijd een opening overblijven, die alleen een lucht- en waterdichte afsluiting kan geven als die opening wordt opgevuld door haemorrhoïdaal weefsel. Het is weefsel dat maakt dat wij als sociale wezens deze wereld kunnen bevolken en waarvoor we de schepper dagelijks op onze blote knietjes mogen bedanken. Pas als dit prachtige weefsel geïrriteerd 
wordt door passage van harde feces kan het verzakken en uitzakken. Het vergrote en niet meer op zijn originele plaats zittende weefsel gaat klachten geven van bloedverlies en prolaps. Het prolaberende haemorrhoïdaal weefsel kan tractie geven aan de extreem gevoelige anale huid. Dan ook pas treedt pijn op "van de aambeien". Het haemorrhoïdale weefsel is namelijk altijd bedekt door anaal en rectum slijmvlies dat op zichzelf volkomen gevoelloos is. Ik hoop nu dat $\mathrm{u}$ allen, dit wetende, anders zult gaan aankijken tegen Haemorrhoïden.

Mogelijk dat u ook wat verrast bent door een wat andere kijk op de meest voorkomende aandoening van de mens, namelijk peri-anale jeuk. Dit is een niet al te zwaar lijden maar iets dat vrijwel ieder mens wel eens in zijn leven 
meemaakt. Men heeft talloze theorieën bedacht van overgevoeligheden voor wasproducten waarmee het ondergoed gewassen werd tot vreselijke

huidaandoeningen. De waarheid is echter een heel simpele. Bij defaecatie verlaat niet alles het lichaam en vooral als de ontlasting wat plakkerig is blijven er restjes achter in het anale kanaal. Deze resten veroorzaken inwendig wat irritatie en zetten de kringspier aan om na te blijven knijpen op momenten dat men niet meer op het toilet zit of in de badkamer is. De naar buiten geknepen restjes komen dan op de peri-anale huid terecht en veroorzaken daar locaal eczeem. Men is dan niet in staat deze restjes meteen te verwijderen en het gevolg is een aantal reacties. De huid wordt rood en begint te jeuken. De huid gaat net als elders op het lichaam vocht afscheiden. Dit vocht lost de 
ontlastingsrestjes op en is verantwoordelijk voor de bruine sporen of 'remsporen' zoals het in de volksmond heet. De oplossing voor dit probleem is kinderlijk eenvoudig. Als men ziet dat de ontlasting plakkerig is, het gebruik van de Wc-borstel nodig is en er meer dan tien velletjes Wc-papier nodig zijn dan lukt het kennelijk niet om het gebied op de gebruikelijke wijze te reinigen, en dan zou men zichzelf een klysma moeten toedienen om het anorectum van binnenuit te reinigen. Een van binnenuit gereinigd kanaal zal geen resten meer herbergen en dus komen er peri-anaal geen resten meer. Er ontstaat dus geen eczeem en de jeuk is over. 
Van nu af was ik, zoals Greep het noemde "the rear-end admiral". De belangstelling voor het laatste deel van de tractus gastro-intestinalis moest wel toenemen omdat mijn polikliniek bijna bezweek onder het grote aanbod van deze pathologie. Patiënten kwamen niet alleen uit de stad maar al gauw vanuit de hele regio en heel Nederland. Kennelijk sprak het zich rond dat er in Maastricht iemand zat, die hierin gespecialiseerd was. Je moet dit echter wel met een slok zout nemen. De waarheid is dat dit een terrein is waar de meeste chirurgen niets vanaf weten en sterker nog ook niets vanaf willen weten. Men vond het alleen maar praktisch om patiënten met proctologische aandoeningen naar elders te kunnen sturen. En dit gebeurde dus in ruime mate. In de bulk van patiënten met haemorrhoïden en 
fissuren echter waren ook nog al wat patiënten met continentieproblemen. Hier bestond eigenlijk geen behandeling voor en de meesten kregen een blijvend stoma. Als men incontinent was geworden door een ruptuur bij een bevalling bestond er nog een oplossing door de uiteinden van de geruptureerde sfincter aan elkaar te hechten. Er waren echter zovele aandoeningen die leiden tot continentie-klachten, dat de anal repair zeker voor de meeste niet toereikend was. Men kon incontinent worden door zenuwaandoeningen, door geboorteafwijkingen en door infecties. De anal repair was hiervoor volmaakt ongeschikt. Het lezen over en zich verdiepen in deze materie maakte dat er ook oplossingen kwamen. De tijd was kennelijk rijp voor nieuwe denkbeelden. Gelijktijdig ontstond de 
dynamische gracilisplastiek (DGP) in Maastricht en London, de Artificial Bowel Sfincter (ABS) in Kopenhagen en Nantes en de Sacrale Zenuw Stimulatie (SNS) in Erlangen. Dit waren alle verschillende technieken die weer wat hoop gaven voor fecaal incontinenten. In alle gevallen waren het Europese centra die experimenteerden met nieuwe toepassingen van Amerikaanse producten. In de Verenigde Staten worden nieuwe ontwikkelingen nogal gefrustreerd door de FDA, waardoor het soms decennia duurt voordat Amerikaanse collega's methodes mogen gebruiken die hier al tijden bekend zijn.

De Dynamische Gracilisplastiek (DGP) ontstond door dierexperimenten waarbij de cardiomyoplastie werd uitgetest op honden. De gedachte was: als het mogelijk is om een spier zodanig 
te veranderen dat hij ritmisch contraheert, simultaan met het hart, waarom zou het dan niet mogelijk zijn om een getransponeerde gracilisspier te dwingen om continue te contraheren rond de anus. Dit bleek in de praktijk ook werkelijk uitvoerbaar. Een spier die van nature snel moe wordt kan door elektrische stimulatie zodanig veranderen dat hij onvermoeibaar wordt. De stimulatie, toegediend met een geïmplanteerde stimulator, dwingt de spier tot contractie zonder dat de menselijke geest hiervoor nodig is. Deze onvermoeibare spier die automatisch contraheert geeft aan de gracilisspier net die kenmerken die nodig zijn voor een goede sfincterfunctie en dus voor continentie. Een afstandsbediening maakt het mogelijk de stimulator uit te schakelen en dus passage van faeces mogelijk te maken. Na defecatie kan de 
spier weer geactiveerd worden door de geïmplanteerde pacemaker weer aan te switchen. De uitwerking was goed en vele patiënten ondergingen deze ingreep. Collegae Soeters en Spaans waren degenen, die mij steunden in die eerste tijd van nieuwe ontwikkelingen. In de wereld kwam dit als een volslagen verrassing. Eindelijk was er een mogelijkheid buiten de anal repair om fecale incontinentie te bestrijden. Toch bleek de ingreep niet altijd veilig. Er kwamen nogal wat infecties voor. Maar aan de andere kant was het een ingreep die alleen gedaan werd als ultimum refugium voor hen die geen andere optie meer hadden dan een stoma te accepteren voor de rest van hun leven. Vrijwel gelijktijdig liep in Londen collega Norman Williams rond met een soortgelijk idee. Hij gebruikte geen ingebouwde stimulator maar 
stimuleerde als het nodig was van buiten af. Dit bleek nogal wat emotionele stress op te roepen bij veel patiënten. Zij betwijfelden of ze snel genoeg de zender konden aanswitchen bij het eerste dranggevoel. Williams nam onze methode snel over.

De Artificiële Sfincter ( $A B S$ ) rond de anus is een opblaasbare cuff rond de eigen sfincter, die de anus dichtdrukt in rust zodat geen passage mogelijk is. De cuff is verbonden met een ballon die retroperitoneaal in de onderbuik wordt geplaatst. Door middel van drukken op een pompje dat in scrotum of labium geïmplanteerd wordt, kan het vocht uit de cuff naar de ballon getransporteerd worden. De cuff staat dan open en laat passage van feces toe. De overspanning in de ballon dwingt de vloeistof weer terug naar de cuff die vervolgens de 
anus weer dichtdrukt. Het is een logisch systeem dat goed blijkt te werken en een vrijwel volledige continentie kan geven. Er bestaat hier echter een groot gevaar voor infecties. De implantatie van lichaamsvreemd materiaal zo vlak bij de anus is bijna vragen om ontstekingen. Het infectie percentage loopt ondanks de goede antibiotica profylaxe op tot wel $30 \%$. Ook hier geldt: de patiënten moeten de risico's kennen maar hebben nauwelijks een andere keuze. Collega Christiansen uit Kopenhagen was de eerste die dit idee adapteerde vanuit de urologie waar men soortgelijke cuffs gebruikte rond de ureter. De cuffs worden qua grootte aangepast aan de maat van de anus, maar ze hebben nog altijd wat designfouten en zijn daarom nog niet perfect. De vele complicaties maken dat deze methode niet erg populair werd in 
de wereld. Toch heb ik in mijn lange carriére zoveel enthousiaste patiënten ontmoet dat het te kort door de bocht zou zijn om deze therapie aan patiënten te onthouden enkel vanwege de angst voor infectie. Bij infectie is het namelijk mogelijk de ABS te verwijderen, het gebied tot rust te laten komen en vervolgens een tweede implantatie te verrichten. Bij talloze patiënten leidde een dergelijke tweede kans tot een zeer succesvol resultaat.

Iets later in de historie ontstond de Sacrale Zenuw Stimulatie, oftewel Sacral Nerve Stimulation ( SNS ). Het is een methode die ontwikkeld is door urologen. In de tachtiger jaren vonden Tanagho en Smidt dat het elektrisch stimuleren van zenuwbundels in het heiligbeen leidde tot oplossing voor urine-incontinentie. Het viel op dat 
patiënten, die incontinent waren voor zowel urine als voor feces ook goed reageerden op de sacrale zenuwstimulatie voor hun fecaal probleem. Degene die dit als eerste oppikte en voor fecale incontinentie ging toepassen was collega Matzel uit Erlangen. Hij startte eind negentiger jaren met een trial bij patiënten met puur anale incontinentie. In Maastricht waren collega's Janknegt en van Kerrebroeck terzelfder tijd bezig met deze behandeling bij urineincontinentie. Wij participeerden in die eerste multicenter trial van Matzel en deden een enorme ervaring op in de behandeling van patiënten met faecale problematiek. In de loop van de tijd werd de methode op enkele fronten aangepast, maar het principe bleef gelijk. De electrode werd via een holle naald in een foramen in het sacrum 
gebracht en via een transcutane verbindingskabel uitwendig gestimuleerd. Dit gaf de mogelijkheid om met uitwendige middelen eerst uit te testen of de stimulatie het gewenste effect had voordat men de zeer kostbare pacemaker zou implanteren. De levensduur van een pacemaker is beperkt. Wij constateerden echter dat patiënten 's nachts vrijwel nooit hoefden te defeceren en vroegen de patiënten de stimulator 's nachts uit te zetten. Dit verlengde de levensduur van de pacemakers met wel 30\% en reduceerde dus ook de kosten met 30\%. Het precieze werkingsmechanisme van deze sacrale zenuwstimulatie is tot op heden nog niet gevonden, maar het werkt in ieder geval! Omdat er weinig tot geen complicaties voorkwamen bestond er een liberale toepassing van deze methode en ontdekten we dat ook 
obstipatie hiermee uitstekend behandeld kon worden. Ook onbegrepen pijnen bleken in enkele gevallen goed te reageren op deze therapie. Een speciale groep patiënten reageerde buitengewoon goed. Dit waren jonge vrouwen die een verschrikkelijke obstipatie hadden met een defecatiefrequentie van soms maar eenmaal per maand. Deze meisjes hadden daarbij enorme buikpijnen waardoor ze vaak van school moesten verzuimen en dus onevenredig vaak hun klas moesten doubleren. Jonge mensen die hun opleiding in gevaar zien komen en die ook hun ontwikkeling van puber tot volwassene verstoord zien raken door deze vormen van obstipatie, blijken in een hoog percentage te genezen van deze aandoening waarvoor voorheen geen enkele oplossing was. 
Het stimulatie verhaal is zeer intrigerend, maar het werkingsmechanisme blijft in mysteries gehuld. Nog intrigerender wordt het als een zenuw ver weg van het target orgaan geprikkeld blijkt te kunnen worden en ook een therapie voor incontinentie blijkt te zijn. De nervus tibialis is gemakkelijk te bereiken net boven de enkel. Hier blijkt een niet continue stimulatie genoeg te zijn om mensen continent te krijgen. Waarschijnlijk zijn het de takken van de nervus ischiadicus die vlak langs de bekkenbodemzenuwen lopen en waarschijnlijk in de hersenen net naast het continentiecentrum terechtkomen die een mede-activatie van dit continentiecentrum teweegbrengen. Het is natuurlijk een groot voordeel als een therapie aangeboden kan worden 
in een gebied dat niet zo beladen is en door taboes afgeschermd. Op dit moment echter kunnen we deze therapie alleen in onderzoeksetting toepassen en moeten de patiënten voor elke stimulatie sessie naar het AZM reizen. Als de studie voltooid is en de uitkomst goed, zullen we eerst nurse practitioners en physician assistents moeten opleiden om de therapie overal in het land te kunnen aanbieden.

Niet alle therapieën voor fecale incontinentie maken gebruik van ingewikkelde apparatuur. Sommige zijn heel simpel en eenvoudig te begrijpen. Bij mijn studies naar haemorrhoïden vertelde ik $\mathrm{u}$ al dat het gezwollen haemorrhoïdale weefsel binnen de samengetrokken kringspier voor een waterdichte afsluiting kan zorgen. Voortbouwend op dit idee ontstond de 
gedachte om onder het anale slijmvlies een vulmiddel te spuiten om de anus dicht te kunnen drukken binnen de gecontraheerde sfincter. Het materiaal (in ons geval Silicone) blijkt wel wat te helpen maar het succespercentage staat in geen enkele verhouding tot de eerder genoemde operatieve methodes. In een lange follow up van deze patiënten vonden we ook een door niemand eerder beschreven complicatie, namelijk de vorming van uiterst pijnlijke granulomen rond het geïnjecteerde materiaal. Dit maakte dat deze granulomen verwijderd moesten worden uit het gebied rond de anus. Deze injectietherapie heeft net als bij ons nergens veel opgeld gedaan.

Veel interessanter is de herontdekking van een millenniumoud principe, namelijk het gebruik van water. Met 
behulp van water kan men namelijk de darm leegspoelen. Het principe "uit een lege darm kan men niets meer verliezen" is niet alleen simpele boerenwijsheid maar blijkt ook volkomen waar te zijn. De oude Egyptenaren wisten 5000 jaar geleden al dat het nuttig kon zijn de darm leeg te spoelen en beschreven dit in de Papyrus Ebers. Ook de Grieken en Romeinen kenden dit principe. In de middeleeuwen was clistreren een volkomen geaccepteerde therapie en dit liep door tot in de Franse tijd. Voltaire beschrijft de dokters die met een clistreerspuit achter hun patiënten aanzaten. De Victoriaanse preutse tijd echter maakte het onmogelijk over zaken als incontinentie na te denken en zeker erover te spreken. Zo kon het gebeuren dat een volkomen normale behandeling zoals het spoelen van de darm volledig 
verdween uit het arsenaal van de colorectaal geïnteresseerde arts. Pas twee eeuwen later, vrijwel gelijktijdig, ontstond in Aarhüs en Maastricht hernieuwde belangstelling voor dit onderwerp. Proefschriften in beide universiteiten onderstreepten deze wederopleving na 200 jaar van volledige stilte. Het gebruik van water is van groot voordeel in gebieden waar men zich niet de kostbare methoden van implantaten kan permitteren. De methode is echter ook in het rijke westen een eerstelijns optie voor behandeling van fecale incontinentie. Alleen de patiënten die absoluut niet vooruit kunnen met spoelen komen in aanmerking voor de eerder beschreven operatieve methoden. Het spoelen gebeurt met waterpompjes die qua kosten erg meevallen in vergelijking met de dure implantaten van de eerder 
genoemde operaties. Het prudent omgaan met water biedt enorme kansen, ook in armere delen van de wereld. Het water dient echter altijd schoon te zijn. En men kan het alleen dan gebruiken als men het ook veilig kan drinken. Het gebruik van Nijlwater kan een ernstige "wraak van de Farao" uitlokken.

Alle methoden die de laatste decennia ontwikkeld zijn maken dat de noodzaak om nog tot een stoma over te gaan om incontinentie te behandelen tot bijna 0 gereduceerd is. Bij de behandeling van patiënten met anale aandoeningen volgen we tegenwoordig een schema waarbij eerst simpele methodes worden uitgeprobeerd alvorens we overstappen naar een operatieve meer ingenieuze therapie. Zo werkend komt het tegenwoordig bijna niet meer voor 
dat het aanleggen van een stoma nodig is.

Niet alleen practisch bezig zijn in deze speciale tak van de gezondheidszorg heeft mij geboeid, maar ook de organisatorische kant. Ik was met enkele vrienden in Europa medeoprichter van de European Association of Colo Proctology en ook betrokken bij de samensmelting ervan met de ECCP tot ESCP. Het internationale deel van het werk hield ook in dat ik vaak op pad was voor de International Society of University Colon and Rectum Surgeons en voor de American Society of Colon and Rectal Surgeons. Van enkele van deze verenigingen ben ik inmiddels ook erelid.

Met enkele vrienden maakten we ons 20 jaar geleden zorgen over het openstellen van de grenzen voor alle beroepsgenoten die zich vrij konden 
vestigen overal in Europa. Daarom richtten wij een onderafdeling op van de EBSQ in de coloproctologie en organiseerden examens overal in Europa om een certificaat te behalen dat in heel Europa erkend zou worden.

Werkend in deze niche van de geneeskunde blijkt steeds vaker dat er veel overlap bestaat en veel gemeenschappelijks met andere specialismen zoals de urologen, de functioneel-gynaecologen, de psychiaters en sexuologen en de bekkenbodemtherapeuten. Al jaren geleden richtten we daarom hier in Maastricht het Bekkenbodemcentrum op, onder de bezielende leiding van Bary Berghmans. De collegae van Koeveringe en Vrijens, Link en Weemhof, Leue en Melles, en Lilian Smeets vormen samen met Breukink 
en mij zelf de kern van dit

samenwerkingsverband. Hoewel dit samenwerkingsverband goed

functioneert is de stap om een

gezamenlijke huisvesting te realiseren

om het voor de patiënt gemakkelijker te

maken en op één plaats alle zorg te

centraliseren nog niet gerealiseerd.

Een nieuwe huisvesting met wat

essentiële voorzieningen lijkt geen

overbodige luxe. Ik heb tot afgelopen

week gewerkt op een polikliniek die

niet over een toilet voor patiënten

beschikte. Het is redelijk gènant als op

de plaats waar de meeste fecaal

incontinenten van Europa komen een

dergelijke voorziening ontbreekt. Ik

weet wel dat gebouwenlijke

voorzieningen ondergeschikt zijn aan

de bezielende mensen die er werken,

toch zou het management er eer mee inleggen als deze voorziening snel 
gerealiseerd werd in de nieuwe bekkenbodem polikliniek, een plek waar alle patiënten samen komen om in een keer alle aspecten van hun nare en levensbepalende aandoening te behandelen. Het leven van mensen met aandoeningen aan anus, urinewegen en functionele aandoeningen van geslachtsorganen wordt op een dermate gigantische wijze beïnvloed en heeft een zodanige impact op het geestelijk welzijn dat goede behandeling een enorm positief effect zal hebben, niet alleen op de aandoening zelf, maar ook op alle neveneffecten en ook op de kosten.

Mijn heer de rector, in de afgelopen 38 jaar heb ik in het AZM alle gelegenheid gehad om mijn ideeën ten uitvoer te brengen met een directie die in mij geloofde en mij de financiële ruimte 
bood om mijn kostbare "hobby" te kunnen uitvoeren. Vanaf de eerste dag ,1 mei 1976, tot de laatste, 31 maart 2014, ben ik "fluitend" naar mijn werk gegaan en 's avonds weer "fluitend" naar huis gegaan. Dit betekent dat ik mijn werkzame leven op een goede en vruchtbare werkplek zat en in goede harmonie met een perfect thuisfront heb kunnen leven. Het thuisfront gunde mij de vrijheid om voor mijn werk over de wereld te reizen. Ik verheug me nu op een nog uitgebreidere en inniger samenwerking met dit thuisfront. Karin en mijn kinderen, schoon- en kleinkinderen: Bompa heeft nu de tijd. Mijn collega's op de chirurgische afdeling dank ik voor zovele jaren van harmonieuze samenwerking en de leiders Gauke Kootstra en Michel Jacobs voor de ruimte die ze me gaven. Collegues from all over the world: thank 
you for all cooperation in research and the opportunity you gave me to speak in congresses and workshops and all coöperation in publications. Especially I thank my dear friends Lars and Lena Påhlman (even one of my grandsons is named after you!) and my friend Sören Laurberg and those who cannot be here because of attendance at the EBSQ exams in München today. Ik dank alle collega's in den lande voor alle verwijzingen die het mogelijk maakten om de expertise op te bouwen, alle patiënten die mij vertrouwden en het mij mogelijk maakten nieuwe therapieën te ontwikkelen, alle promovendi om delen van de nieuwe ideeën uit te werken en te beschrijven, alle specialisten uit alle specialismen in het AZM met wie ik afgelopen 38 jaar samen heb gewerkt, alle verpleegkundigen op $\mathrm{OK}$, dagcentrum, 
endoscopie afdeling, van polikliniek, stomazorg, bekkenbodem team, en van de chirurgische verpleegafdelingen voor alle hulp in de loop de jaren. Ik ben veel dank verschuldigd aan het secretariaat, speciaal Eveline en Nicolle die mij 38 jaar voor misstappen behoed hebben. En u allen dank ik voor het geduld om mij aan te horen.

Ik heb gezegd 